\title{
Possible autosomal recessive inheritance of progressive hearing loss with stapes fixation
}

\author{
Cornelia Thies, Michael Handrock, Karl Sperling, André Reis
}

Institüt für

Humangenetik,

Virchow-Klinikum,

Humboldt Universität

zu Berlin,

Augustenburger Platz

1, D-13353 Berlin,

Germany

C Thies

K Sperling

A Reis

Department of

Otorhinolaryngology,

Allgemeines

Krankenhaus

Heidberg, Tangstedter

Landstr 400, D-22417

Hamburg, Germany

$M$ Handrock

Correspondence to:

Dr Reis.

Received 5 April 1995

Revised version accepted

for publication

for publication 1996

\begin{abstract}
Four sibs with progressive, bilateral conductive hearing loss are presented. Symmetrical hearing loss averaging 30-60 dB $(0 \cdot 125-8 \mathrm{kHz})$ became apparent between 8 and 24 years of age. Tympanotomy showed a fixed stapes either through ossified stapedius tendon or through a bony bridge from the stapes to the pyramidal eminence in all patients. After surgical removal of the bony tendon hearing was normal. Both parents, four other sibs, and all grandparents had normal hearing. This family and a further published case suggest a possibly recessive inheritance of this form of conductive hearing loss.

(f Med Genet 1996;33:597-599)
\end{abstract}

Key words: stapes fixation; conductive hearing loss; autosomal recessive; ossicular malformations.

Conductive and sensorineural hearing loss is of genetic origin in between $20 \%$ and $60 \%$ of cases. Both conductive and sensorineural hearing loss is found as part of recognisable syndromes as well as without any associated abnormality. ${ }^{12}$ Generally, genetic abnormalities are more often expressed as sensorineural hearing loss than as conductive hearing loss. Nevertheless, at least 50 different syndromes with conductive hearing loss caused by dysplasia or fixation of the ossicles of the middle ear or by malformations of the external auditory canal have been described. ${ }^{2}$
I

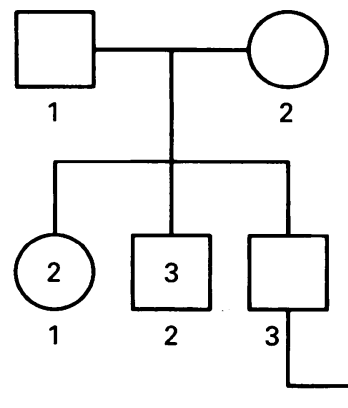

2

II
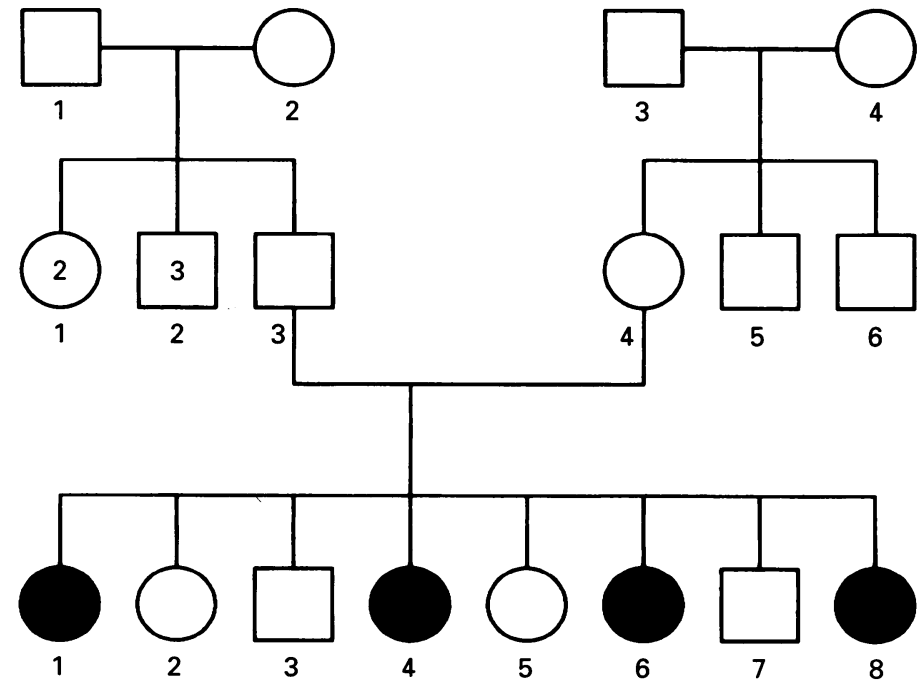

III
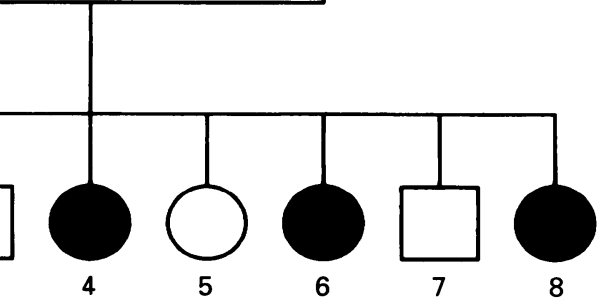

Figure 1 Pedigree of family with progressive hearing loss with stapes fixation from northern Germany. Filled symbols denote affected subjects.
The most common genetically transmitted form of isolated conductive hearing loss is otosclerosis. Its frequency ranges between 0.2 and $2 \% .^{3}$ The basic defect is ossification of the stapes footplate causing fixation of the stapes and preventing transmission to the inner ear. The aetiology is unknown and is considered to be transmitted either autosomal dominantly with incomplete penetrance and variable expression or through the combined action of several additive genes (polygenic inheritance). ${ }^{4}$ Other isolated genetic malformations of middle ear ossicles include incudostapedial disconnection, which is autosomal dominantly inherited. $^{5}$

Recessive inheritance is observed in fixation of the malleus or incus or both. ${ }^{67}$ Different degrees of malformation up to total absence of the stapes have been described although no familiality has been reported. ${ }^{8}$ All these forms of malformation result in conductive hearing loss and can only be differentiated through tympanotomy.

We present here a family with a possibly new autosomal recessive form of hearing loss caused by stapes fixation owing to ossified stapes tendon. Four affected sibs show a similar clinical picture and pathological changes of the stapes tendon.

\section{Case report}

SIB $1($ III 1$)$

A 44 year old woman, the first daughter of a non-consanguineous family from northern Germany (fig 1), was first referred at the age of 24 years with progressive hearing loss in her right ear. No external ear anomalies were apparent. The tympanic membrane was intact. There were no findings or history of otitis media. Audiometry showed a symmetrical conductive hearing loss averaging $40 \mathrm{~dB}$ at $2 \mathrm{kHz}$ in the right ear and $30 \mathrm{~dB}$ in the left ear $(0 \cdot 125-8 \mathrm{kHz})$ (fig 2). Rinne test was bilaterally negative and stapedial reflex was also negative.

Tympanotomy in the left ear showed a stapes fixed by a bony bar from the neck of the stapes to the pyramidal eminence parallel to the stapedial tendon (fig 3). The stapes footplate was normal with no evidence of previous infection or otosclerosis. After removal of the bony bar, hearing was normalised. Subsequent tympanotomy in her right ear produced the same findings. Normalisation of hearing after surgery was documented through audiometry (5-10 dB from $0 \cdot 125-8 \mathrm{kHz}$ ).

SIB $2($ III 4$)$

The sister of case 1, a 37 year old woman, first noticed hearing loss at the age of 21 years. 
Frequency in $\mathrm{kHz}$

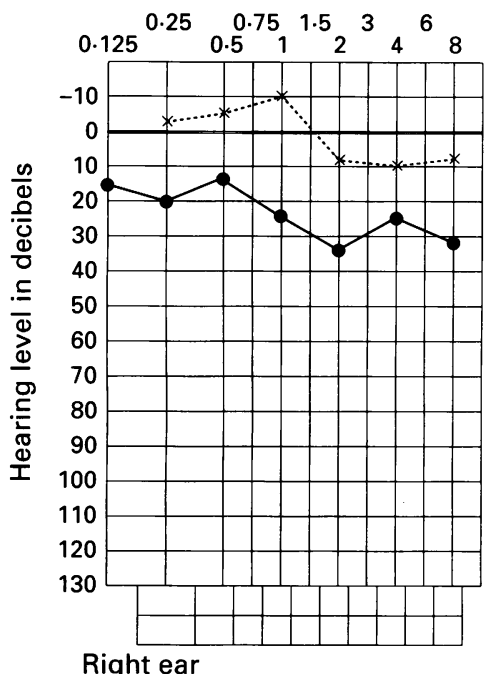

Frequency in $\mathrm{kHz}$

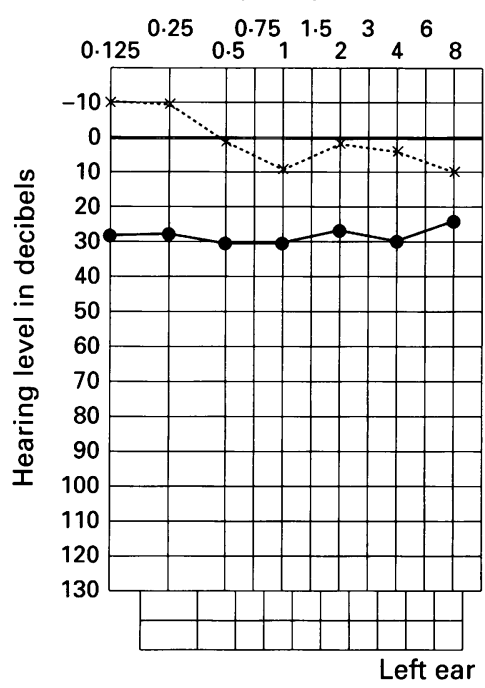

Figure 2 Audiogram of sib 1 (III.1 in fig 1) at the age of 24 years showing bilateral conductive hearing loss of approximately 30-40 dB at 0.125-8 kHz. Dotted lines denotes bone conduction, solid lines air conduction.

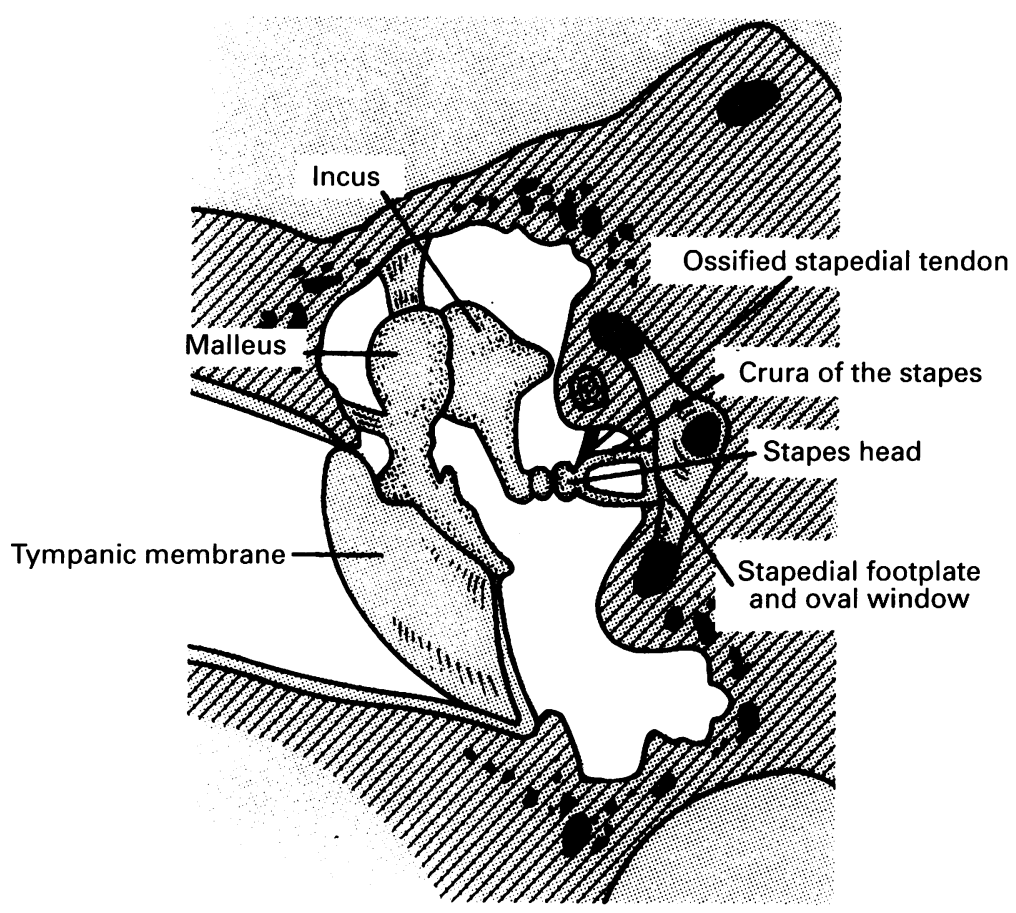

Figure 3 Schematic drawing of the middle ear ossicles showing the location of the stapes tendon ossification and the place of the bony bridge parallel to the stapes tendon, respectively (adapted from reference 8, page 18.8).

Audiometry showed conductive hearing loss of $30-50 \mathrm{~dB}$ at $0 \cdot 125-2 \mathrm{kHz}$ in her right and $30-40 \mathrm{~dB}$ at $0 \cdot 125-8 \mathrm{kHz}$ in her left ear. The stapedial reflex was negative. Left tympanotomy showed ossification of the stapedial tendon, which was cleaved. Postoperatively audiometry was normal. Tympanotomy in her right ear is still pending. Progression of hearing impairment in this ear over the years was documented by renewed audiometry.

SIB $3($ III 6 )

The sister of cases 1 and 2 , a 32 year old woman, first complained about hearing loss when she was 8 years old. Audiometry showed

symmetrical conductive hearing loss averaging $30-50 \mathrm{~dB}$ at $0 \cdot 125-2 \mathrm{kHz}$. The stapedial reflex was negative. Tympanotomy in the left ear showed an ossified stapedius tendon which was cleaved, as in the other cases. Normal hearing in this ear was restored. In her right ear a bony bridge parallel to the normal stapedial tendon and a deformity of the head of the stapes was found. Removal of the bony bridge did not restore normal hearing. A second tympanotomy 16 years later now showed a shortened crus of the incus, the head of the stapes was absent, and connective tissue had developed between the crus of the incus and the stapes (fig 3), possibly a result of the first operation. Cleavage of the incudostapedial joint did not restore normal hearing. Finally a stapes plastic was implanted which then restored normal hearing.

SIB 4 (III·8)

The 26 year old sister first presented at the age of 17 years with similar findings on audiometry and tympanotomy to sib 1 with a bony bridge parallel to the stapes tendon in both ears. Surgery restored normal hearing.

Both parents and four other sibs (two girls and two boys) had normal hearing, which was audiometrically verified. All grandparents are dead but hearing is reported to have been normal in all except the maternal grandfather, who developed a mild hearing loss at the age of 65 years. A cytogenetic investigation of both parents and two affected sibs (III 1 and III 6 ) showed a normal karyotype.

\section{Discussion}

A family with four sibs with bilateral stapes fixation is presented. Both parents and four other sibs have normal hearing which was verified through audiograms in all cases. No family history of hearing loss, except one case of probable presbyacusis in the maternal grandfather, is documented. Age of onset was variable with progressive hearing loss starting between the ages of 8 (III-4) and 24 years (III-1). Patients reported progressive hearing loss which after three to five years reached $30-50 \mathrm{~dB}$ at $0 \cdot 125-8 \mathrm{kHz}$. Hearing was completely normalised after surgical cleavage of the ossified stapedial tendon or the bony bridge, respectively. After 20 years of follow up the hearing in sib 1 is still normal.

Sib 3 had a dysplastic stapes head in her right ear in addition to a bony bridge. This second pathology was probably the cause of persistence of hearing loss after the first tympanotomy. Together with possible secondary changes caused by the surgery, a stapes plastic finally became necessary. This did then restore normal hearing, confirming the conductive nature of the hearing impairment in this sib also.

Among the middle ear ossicle anomalies the stapes is the most often affected ossicle. Some authors have discussed a relationship between malformations of the stapes and the persistence of the A stapedia, a ramification of the A carotis 
interna. During embryological development the stapes is formed out of the stapesblastema, which grows along the A stapedia. Normally the A stapedia obliterates during the third embryonic month. Persistence results in an increase of the calibre of the A stapedia and possibly leads to necroses in the blastema owing to compression. This can even lead to partial or total agenesis of the stapedial crura or to dysplasia of the stapes. ${ }^{9}$ In the family presented the persistence of the A stapedia is probably not the reason for dysplasia, since ossification became apparent only later in life. Nevertheless, other similar vascular processes might have been responsible for the aberrant ossification of either the tendon itself or the formation of the adjacent bony bridge described.

The most important differential diagnosis is otosclerosis. In both diseases the stapes is involved in an abnormal ossification process, but different parts of the stapes are affected. In otosclerosis, ossification of the stapes footplate progressing to involvement of the entire oval window can be observed. The otosclerotic change may spread from the oval window to the round window and the basal turn of the cochlea and into the stapes. ${ }^{3}$ In the patients described here, tympanotomy showed an ossified stapedial tendon and a bony bar parallel to the tendon, respectively, which excludes otosclerosis.

The similarity of the stapedial changes observed in all four sibs, together with the normal hearing in both parents and grandparents, suggests autosomal recessive inheritance. The fact that both parents as well as the grandparents of each line are not affected argues against the possibility of autosomal dominant inheritance. Although we cannot completely rule out mitochondrial inheritance with heteroplasmy in the mother, the specific nature of the changes observed as well as the similar degree of severity in the sibs argues against such a possibility.

In the last 10 years several cases with ossification of the stapedial tendon or a bony bridge parallel to the tendon similar to those described here have been published, ${ }^{10-14}$ although only two were familial. ${ }^{1314}$ Two sibs with similar findings were described by Grant and Grant, ${ }^{13}$ a 9 year old girl and her older brother with ossified stapedial tendons. Although the authors did not mention whether the parents had normal hearing, this is probably the case as any hearing loss would probably have been noticed. Therefore this family is also compatible with a recessive pattern of inheritance. Another case was published by Kinsella and Kerr, ${ }^{14}$ describing a mother and her 5 year old daughter. Tympanotomy showed a bony bar extending to the stapes head from the pyramid, superior to a normal stapedius tendon. This family would suggest autosomal dominant inheritance. Several genetic factors, both dominant and recessive, could possibly lead to aberrant calcification of the stapes tendon itself or to formation of an adjacent bony bridge. As only tympanotomy can show the true nature of the underlying pathology, the full extent of this form among patients with conductive hearing loss remains unclear.

In summary we present a family with a familial form of progressive conductive hearing loss owing to abnormal calcification of a tendon of the stapes, an inner ear ossicle. The inheritance pattern is suggestive of an autosomal recessive condition.

1 Kessler L. Genetisch determinierte Hörstörungen. In: Kessler L, ed. Fehlbildungen in der Otorhinolaryngologie. Berlin: Springer, 1989:44-6.

2 Nadol JB. Hearing loss. N Engl f Med 1993;329:1095-7.

3 Ben Arab S, Bonaiti-Pellie C, Belkahia A. A genetic study of otosclerosis in a population living in the north of Tunisia. Ann Genet (Paris) 1993;36:111-16.

4 Gorlin RJ. Genetic hearing loss with no associated abnormalities. In: Gorlin RJ, Toriello HV, Cohen MM Jr, eds. Hereditary hearing loss and its syndromes. New York: Oxford University Press, 1995:43-61.

5 Higashi K, Yamakawa K, Itani O, Togawa K. Familial ossicular malformations: case report and review of literature. Am $\mathcal{F}$ Med Genet 1987;28:655-9.

6 Funasaka S. Congenital anomalies without malformations in the external ear. Arch Otorhinolaryngol 1979;224:231-40.

7 Escher F, Hirt H. Dominant hereditary conductive deafness through lack of incus-stapes junction. Acta Otolaryngol 1968;65:25-32.

8 Mündnich $\mathrm{K}$, Terrahe $\mathrm{K}$. Malformations of the ear. In: Berendes J, Link R, Zöllner F. ENT-medical science in practice and hospital. Stuttgart: Georg Thieme, 1964:18.79.

9 Otto HD, Gerhardt HJ. Steigbügelmissbildungen. Acta Otolaryngol 1970;70:35-44.

10 Meuser W. Schalleitungsschwerhörigkeit durch verknöcherte Stapediussehnen. Laryngol Rhinol 1977;56:1213.

11 Jecker P, Hartwein J. Die Verknöcherung der Stapediussehne als seltene Ursache einer Schalleitungsschwerhörigkeit. Laryngo-Rhino-Otol 1992;71:344-6.

12 Cremers CWRJ. Congenital stapes ankylosis by elongation of the pyramidal eminence. Ann Oto Rhino Laryngol 1986; 95:167-8.

13 Grant WE, Grant WJ. Stapedius tendon ossification: a rare cause of congenital conductive hearing loss. $\mathcal{F}$ Laryngol Cause of congenital con $1991 ; 105: 763-4$.

14 Kinsella JB, Kerr AG. Familial stapes superstructure fixation. $\mathcal{F}$ Laryngol Otol 1993;107:36-9. 